\title{
The Impact of Systems Analysis and Design Performance on Learning Advanced Systems Development Methodology
}

\author{
Kelvin C. K. Wong and Fion S. L. Lee
}

\begin{abstract}
Systems analysis and design is a complex and challenging process. In order to prepare information systems (IS) major students for employment, the Association for Computing Machinery (ACM) and the Association for Information Systems (AIS) developed the IS 2010 Curriculum Guidelines for Undergraduate Programme in Information Systems which identify the systems analysis and design course as one of the seven core courses in an IS undergraduate curriculum. This study aims to investigate the impact of student performance in Systems Analysis and Design course on the learning of an advanced information systems development methodology course. In addition to a thorough discussion on the findings, limitations of the study and further research were identified.
\end{abstract}

Index Terms-Systems analysis and design, information systems development methodology, gender difference, information systems.

\section{INTRODUCTION}

Systems analysis and design is a complex and challenging process that takes places in businesses and organizations in which information systems are developed. With the aim of preparing information system (IS) major students for employment, the Association for Computing Machinery (ACM) and the Association for Information Systems (AIS) developed the IS 2010 Curriculum Guidelines for Undergraduate Programme in Information Systems which identify the systems analysis and design course as one of the seven core courses in an IS undergraduate curriculum [1], [2]. Due to its importance, a significant amount of research has been conducted to enhance students learning in this course. Most of them focused on the use of game-based learning [3]- [6], constructionist approach [7], project work [8], [9], active learning [10], [11] and flipped classroom approach [12] to enhance student learning. Since assessing how far the students have achieved the learning outcomes is an important element in teaching and learning, some researchers conducted studies in formative assessment [13] and summative assessment [14] in systems analysis and design course. Another research direction is to study the course contents [15], [16] and the perceptions of educators and practitioners on the importance of skills and knowledge being taught in a systems analysis and design course and the class time devoted to each [2], [17].

Manuscript received September 6, 2018; revised November 12, 2018.

Kelvin C. K. Wong and Fion S. L. Lee are with Department of Computer Science, Hong Kong Baptist University, Hong Kong, China (e-mail kckwong@comp.hkbu.edu.hk, fionlee@comp.hkbu.edu.hk).
Although considerable research has been conducted in systems analysis and design course, studies on investigating its relationship with other courses are still very rare. The current available researches include the case study of combining database knowledge with systems analysis and design course to let students practicing the development of a ticket sales system [18]. Another study found students could have better performance in systems analysis and design class after completed the programming course [19]. Apart from systems analysis and design and the traditional computer science courses, researchers also proposed incorporating IT entrepreneurship class to the information systems curriculum for empowering students to create business through innovation [20]. These results highlighted course does not support students' learning individually, instead, a good arrangement and collaboration between courses can enhance the learning outcomes in large extent. In view of the limited studies in this aspect, this study aims to examine the impact of the student performance in systems analysis and design course on the learning of another related course.

\section{THE STUDY}

The purpose of this study is to investigate to what extent the student performance in Systems Analysis and Design (SAD) course impacts the study result in another related course. In the curriculum design of an undergraduate information systems programme in a university in Hong Kong, students have to work on a development project in Year 3 study to demonstrate their ability to complete a software development by applying the SAD knowledge. However, the development project is mainly assessed on group basis while all SAD course assessments are individual components. Hence, we determined to adopt another course namely, Information Systems Theory, Methodology and Architecture (IMA), as another target of this study. Both SAD and IMA are the core courses in this undergraduate programme curriculum. SAD is a Year 3 course which introduces an information systems development methodology to students. Students would study system development cycle, object-oriented concepts, UML models, etc. in this course. IMA is a Year 4 course extending students' knowledge of information systems and development methodology through the study of advanced theories and methodologies. This course introduces systems concepts, prototyping, soft systems methodology, advanced object-oriented concepts, etc. It is expected students can appreciate the methodological pluralism in IMA based on the skills and knowledge they gained from SAD. This paper aims 
to present a longitudinal cohort study in which the performance of each student in the same class was observed in both courses. The student performance was measured by the score they obtained in different summative assessments set by the instructors. Pearson's Product Moment Correlation Coefficient was used to determine the closeness of the relationship between the scores in the two courses.

TABLE I: Assessment Methods AND WeIGHTINGS IN THE Two CourseS

\begin{tabular}{lcc}
\hline \hline Assessment & $\begin{array}{l}\text { Systems Analysis } \\
\text { \& Design }\end{array}$ & $\begin{array}{l}\text { IS Theory, methodology } \\
\text { \& Architecture }\end{array}$ \\
\hline Quiz & $16 \%$ & $40 \%$ \\
Term paper & $14 \%$ & $60 \%$ \\
Mid-term test & $70 \%$ & \\
Examination & & \\
\hline \hline
\end{tabular}

The study population included 30 students of which 20 and 10 were male and female respectively. Those students who took the one-year placement in industry were not included in the study sample as they did not take the IMA with their SAD classmates in Year 4. The measurement instruments were the assessment tools such as quiz, test, term paper and final examination used in the course. Table I shows the assessment methods and their weightings in the courses.

\section{RESULTS AND DISCUSSION}

TABLE II: CORRELATION BETWEEN THE ASSESSMENT SCORES OF THE TwO COURSES

\begin{tabular}{lccccc}
\hline \hline & $(1)$ & $(2)$ & $(3)$ & $(4)$ & $(5)$ \\
\hline (1) SAD: Quiz & 1.000 & $.592^{* *}$ & $.534^{* *}$ & $.402^{*}$ & $.735^{* *}$ \\
(2) SAD: Test & & 1.000 & $.778^{* *}$ & $.401^{*}$ & $.704 * *$ \\
(3) SAD: Exam & & & 1.000 & $.361 *$ & $.659 * *$ \\
(4) IMA: Term paper & & & & 1.000 & $.430^{*}$ \\
(5) IMA: Exam & & & & & 1.000 \\
\hline \hline Note: $* p<.05$ and $* * p<.01$ & & & &
\end{tabular}

The aim of this study is to determine the possible association between student performance in systems analysis and design course and the information system theory, methodology and architecture course. Table II shows that there was a high positive correlation between the following pairs of assessment score in SAD and IMA courses:

- quiz score in SAD and examination score in IMA, $r$ $=.735, \mathrm{p}<.01$

- test score in SAD and examination score in IMA, r=.704, $\mathrm{p}<.01$

- examination score in SAD and examination score in IMA, $\mathrm{r}=.659, \mathrm{p}<.01$

and moderate positive correlation between the following pairs were found:

- quiz score in SAD and term paper score in IMA, r=.402, $\mathrm{p}<.05$

- test score in SAD and term paper score in IMA, r=.401, p $<.05$

- examination score in SAD and term paper score in IMA, $\mathrm{r}=.361, \mathrm{p}<.05$

It was not a surprise to have a positive correlation in student performance as measured by assessment scores between the two courses because SAD is an introductory course in information systems development methodology while IMA is an advanced one. Students with better performance in an introductory course would have a more solid foundation to acquire the knowledge taught in an advanced course of the same area. Hence, they could keep their performance in IMA. The same applies, of course, vice versa to the weak students in the SAD. Based on the above preliminary correlation analysis results, we may draw a conclusion that the student performance in SAD could be a predictor of the performance in IMA.

TABLE III: CORRELATION BETWEEN THE ASSIGNMENT SCORES OF MALE STUDENTS IN THE TwO COURSES

\begin{tabular}{lccccc}
\hline \hline & $(1)$ & $(2)$ & $(3)$ & $(4)$ & $(5)$ \\
\hline (1) SAD: Quiz & 1.000 & $.573^{* *}$ & $.460^{*}$ & $.483^{*}$ & $.766^{* *}$ \\
(2) SAD: Test & & 1.000 & $.834^{* *}$ & $.682^{* *}$ & $.710^{* *}$ \\
(3) SAD: Exam & & & 1.000 & .432 & $.605^{* *}$ \\
(4) IMA: Term paper & & & & 1.000 & $.522^{*}$ \\
(5) IMA: Exam & & & & & 1.000 \\
\hline \hline
\end{tabular}

Note: $* p<.05$ and $* * p<.01$

All three assessment scores of SAD were only moderately correlated with that of term paper of IMA and they were only significant at .05. This result does not strongly support our proposition that performance in SAD would directly impact the score in IMA. Hence, we were curious about this and tried to investigate the result from another perspective. Further correlation analysis by gender was conducted. Table III shows the correlation between the assessment scores of male students in SAD and IMA. Their correlations were similar to those in Table II (i.e. analysis for the entire class) except that the correlation coefficients were higher.

TABLE IV: CORRELATION BETWEEN THE ASSESSMENT SCORES OF FEMALE STUDENTS IN THE TWO COURSES

\begin{tabular}{lccccc}
\hline \hline & $(1)$ & $(2)$ & $(3)$ & $(5)$ & $(6)$ \\
\hline (1) SAD: Quiz & 1.000 & .621 & $.759^{*}$ & -.011 & .532 \\
(2) SAD: Test & & 1.000 & $.683^{*}$ & -.291 & $.687^{*}$ \\
(3) SAD: Exam & & & 1.000 & .037 & $.854^{* *}$ \\
(5) IMA: Term paper & & & & 1.000 & -.055 \\
(6) IMA: Exam & & & & & 1.000 \\
\hline \hline
\end{tabular}

Note: $* p<.05$ and $* * p<.01$

Table IV presents the correlation analysis results between the assessment scores of female students in the two courses. To our surprise, No correlation was found in the following pairs:

- quiz score in SAD and term paper score in IMA, r=-.011, $\mathrm{p}>.05$

- examination score in SAD and term paper score in IMA, $\mathrm{r}=.037, \mathrm{p}>.05$

Besides, there was a low negative correlation between the test score in SAD and term paper score in IMA, $\mathrm{r}=-.291$, p>.05. In order to explain this phenomenon, the raw data of each female case was examined. It has been found that there were two exceptional cases. One female student who performed well in SAD in Year 3, but she underperformed in her IMA term paper in Year 4. This may be due to her participation in an auxiliary force in Year 4 which occupied her a lot of time for training and service. Meanwhile, to complete the three term papers of IMA, students should follow the instructions provided in the tutorial classes and 
conduct extensive reference reading and analysis. It is believed this student underestimated the time required to complete a quality paper and spared some time for the auxiliary force service that resulted to a less satisfactory performance than what she could have. Another female student who was not well performed in SAD, but performed well in the IMA term papers because she recognized after the release of the Year 3 grade report that she was at the margin of the next higher degree classification. If she worked hard in Year 4, she might have a chance to get a higher classification in her degree. This motivated her to work harder in every course in Year 4. She spent a lot of time in writing the IMA term papers and with her good writing skill, she finally got high marks in her term papers. Though two exceptional cases were identified, it represented $20 \%$ of the female student study sample. In general, student performance in SAD was positively correlated to their performance in IMA as measured by the various individual assessments.

TABLE V: CROSS TABULATION FOR SAD GRADE AND IMA GRADE GAINED BY STUDENTS

\begin{tabular}{|c|c|c|c|c|c|c|c|c|c|c|}
\hline & & \multicolumn{9}{|c|}{ IMA grade } \\
\hline & & A & A- & $\mathrm{B}+$ & B & B- & $\mathrm{C}+$ & $\mathrm{C}$ & $\mathrm{C}-$ & D \\
\hline \multirow{9}{*}{$\begin{array}{l}\text { SAD } \\
\text { grade }\end{array}$} & A & & & & & & & \multirow{9}{*}{2} & \multirow{9}{*}{1} & \\
\hline & A- & 2 & & & & & & & & \\
\hline & $\mathrm{B}+$ & 1 & 1 & 1 & & & & & & \\
\hline & B & 1 & 3 & 2 & 2 & & & & & \\
\hline & B- & & & 2 & 2 & 2 & & & & \\
\hline & $\mathrm{C}+$ & & 1 & 1 & 1 & 1 & 1 & & & \\
\hline & $\mathrm{C}$ & & & & & 1 & 1 & & & \\
\hline & C- & & & & & & & & & \\
\hline & D & & & & & & 1 & & & \\
\hline
\end{tabular}

The above analysis results show the correlation of individual assessment components between the two courses. We were interested in examining whether there was correlation of letter grade gained by students between the courses. The letter grades are used to indicate the student overall performance in the course. Table $\mathrm{V}$ shows the cross tabulation results for the relationship of student letter grades between SAD and IMA. It gave the general impression that they were correlated. However, we could not obtain the correlation statistics on the letter grades as they were only available for numeric data. Hence, we converted the letter grades to their corresponding grade points according to the scale set by the university. The letter grades to grade points conversion table is shown in Table VI.

TABLE VI: LETTER GRADE TO GRADE POINTS CONVERSION

\begin{tabular}{cc}
\hline \hline Letter grade & Grade point \\
\hline A & 4.00 \\
A- & 3.67 \\
B+ & 3.33 \\
B & 3.00 \\
B- & 2.67 \\
C+ & 2.33 \\
C & 2.00 \\
C- & 1.67 \\
D & 1.00 \\
F & 0.00 \\
\hline \hline
\end{tabular}

Correlation analysis was performed to test the relationship of the grade points gained by students between SAD and IMA. The result reveals that there was a high positive correlation between $\mathrm{SAD}$ grade point $(\mathrm{M}=2.689, \mathrm{SD}=0.561)$ and IMA grade point $(\mathrm{M}=3.089, \mathrm{SD}=0.649), \mathrm{r}=.743, \mathrm{p}<.01$. In other words, the student overall performance in SAD has positive impact on their overall performance in IMA.

\section{LIMITATIONS AND FUTURE STUDIES}

Generalizability of the findings from the present study needs to be cautioned as the data obtained from a small sample. There is a need for further replication of this study. It is frequently the case in research that the study of one problem suggests other problems. This study investigated the impact of student performance in SAD on the learning of IMA. Further research can be conducted to study the impact of other courses such as programming, applied information systems laboratory and information system development project on the learning of SAD and IMA.

Even the students involved in the study were the same batch, but the instructors of the two courses are different. It is suspected the teaching style of the different course instructors may affect the learning results of students. Besides, the continuous assessments of SAD were based on quiz and test while that of IMA was based on term paper. According to the previous studies [21], [22], the students might perform differently in test and the coursework type assessment like term paper. Therefore, due to different course setting, the result of this study might not completely reflect the correlation of students' performance in these two courses. A more reliable result can be derived if the setting of the two courses could be aligned.

It was also found that the learning result might be affected by the circumstance encountered by individual. Investigation solely based on quantitative data is not enough to reflect the phenomenon. Qualitative study, such as interview, can be conducted in the future to study how students perceive the correlation between courses. It can support the course design of a curriculum and improve the programme learning outcomes.

\section{CONCLUSION}

This study attempted to examine the impact of student performance in systems analysis and design course on their learning in Information Systems Theory, Methodology and Architecture which was an advanced development methodology course based on the former one. The findings reveal that student performance as measured by quiz, test and examination in SAD was positively correlated to their performance as assessed by term paper and examination in IMA. Additional analysis in the female student sample showed that there was no correlation or low negative correlation between SAD performances as measured by various assessments and the term paper performance in IMA. To explain the analysis results regarding the female students' performance, further investigation found that two female students' performance in the IMA term paper was unusual due to their personal reasons. On the whole, student performance in SAD is a good predictor of their performance in IMA 


\section{REFERENCES}

[1] H. Topi, J. S. Valacich, R. T. Wright, K. M. Kaiser, J. F. Jr. Nunamaker, J. C. Sipior, and G. J. de Vreede, 2010 Curriculum Guidelines for Undergraduate Programs in Information Systems, Association for Computing Machinery and Association for Information Systems, 2010.

[2] B. N. Guidry, D. P. Stevens, and M. W. Totaro, "The systems analysis and design course: An educators' assessment of the importance and coverage of topics," Journal of Information Systems Education, vol. 22, no. 4, pp. 331-345, 2014.

[3] J. A. Tepper. (2014). "Assessment for learning systems analysis and design using constructivist techniques," The Higher Education Academy. [Online]. Available: https://www.heacademy.ac.uk/system/files/comp-044-p_0.pdf

[4] E. Oh Navarro and A. van der Hoek, "On the role of learning theories in furthering software engineering education," in Software Engineering: Effective Teaching and Learning Approaches and Practices, H. J. C. Ellis, S. A. Demurjian, and J. F. Naveda, Eds. 2008.

[5] A. Baker, E. Oh Navarro, and A. van der Hoek, "An experimental card game for teaching software engineering processes," The Journal of Systems and Software, vol. 75, pp. 3-16, 2005.

[6] T. C. Hainey, T. M. Connolly, M. H. Stansfield, and E. A. Boyle, "Evaluation of a game to teach requirements collection and analysis in software engineering at tertiary education level," Computers and Education, vol. 56, no. 1, pp. 21-35, 2011.

[7] B. Khoo, "Evaluating the effectiveness of the constructionist approach to object-oriented systems analysis and design pedagogy," The Review of Business Information Systems, pp. 59-66, 2009.

[8] K. Surendran, C. Ehie Ike, and C. Somarajan, "Enhancing student learning across disciplines: A case example using a systems analysis and design course for MIS and ACS majors," Journal of Information Technology Education, vol. 4, pp. 257-274, 2005.

[9] K. W. Chuang and K. C. Chen, "Designing service learning project in systems analysis and design course," Academy of Educational Leadership Journal, vol. 17, no. 2, 2013.

[10] B. A. Reinicke and T. N. Janicki, "Increasing active learning and end-client interaction in the systems analysis and design and capstone courses," Information Systems Education Journal, vol. 8, no. 40, 2010.

[11] C. W. Wong, "Empowering students to actively learn systems analysis and design: the success of an entrepreneurial-inspired project in a hybrid learning environment," Information Systems Education Journal, vol. 15, no. 5, pp. 68-83, 2017.

[12] M. Tanner and E. Scott, "A flipped classroom approach to teaching systems analysis, design and implementation," Journal of Information Technology Education: Research, vol. 14, pp. 219-241, 2015.

[13] I. Lavy and A. Yadin, "Team-based peer review as a form of formative assessment - The case of a systems analysis and design workshop," Journal of Information Systems Education, vol. 21, no. 1, pp. 85-98, 2010 .
[14] M. Dick, "Student interview as a tool for assessment and learning in a systems analysis and design course," in Proc. of the 10th Annual SIGCSE Conf. on Innovation and Technology in Computer Science Education, 2005, pp. 24-28.

[15] T. J. Burns, "Defining the content of the undergraduate systems analysis and design course as measured by a survey of instructors," Information Systems Education Journal, vol. 9, no. 5, pp. 4-17, 2011.

[16] S. Wang and H. Wang, "Redesigning the information systems analysis and design course: Curriculum renewal," Journal of Computer Information Systems, vol. 55, no. 1, pp. 30-39, 2014.

[17] B. N. Guidry and D. P. Stevens, "Comparing perceptions of the systems analysis and design course," Journal of Computer Information Systems, vol. 55, no. 1, pp. 40-47, 2014.

[18] T. L. Fox, "Systems analysis, design, and development case study: Medallion theatre - Ticket sales system," Journal of the International Academy for Case Studies, vo. 23, no. 2, pp. 11-17, 2017.

[19] W. C. Wong, "The impact of programming experience on successfully learning systems analysis and design," Information Systems Education Journal, vol. 13, no. 3, pp.15-23, 2015.

[20] C. G. Jones and D. Liu, "Approaches to incorporating IT entrepreneurship into the information systems curriculum," Journal of Information Systems Education, vol. 28, no. 1, pp. 43-58, 2017.

[21] J. T. E. Richardson, "Coursework versus examinations in end-of-module assessment: A literature review," Assessment \& Evaluation in Higher Education, vol. 40, no. 3, pp. 439-455, 2015.

[22] S. Murdan, "Exploring relationships between coursework and examination marks: A study from one school of pharmacy," Pharmacy Education, vol. 5, no. 2, pp. 97-104, 2005.

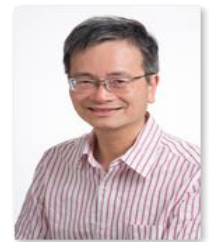

Kelvin C. K. Wong is an assistant professor and the programme director of BS.c (Hons) in computing and information systems at Department of Computer Science Hong Kong Baptist University. His research focuses on information technology in education, systems analysis and design and applications of latent semantic analysis. He has worked on funded projects relating to the development of e-learning system and the application of LSA to student essay writing.

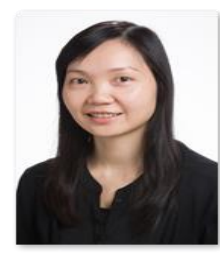

Fion S. L. Lee is a senior lecturer at Department of Computer Science, Hong Kong Baptist University. She graduated with a $\mathrm{Ph} . \mathrm{D}$ degree in information systems. Her research focuses on e-learning, information systems strategy and management, and online community. She has worked on funded projects relating to the development of mobile platform for learning, web-based essay critiquing system, prototype system for e-business strategies formulation. 